дения легких во время анестезии, хирургическая и анестезиологическая тактика при выполнении эзофаготомии. Вечером 11 декабря состоялся ужин для участников ассамблеи, на котором участники знакомились друг с другом и обменивались научным опытом. В пятницу 12 декабря были обсуждены проблемы лечения острой дыхательной недостаточности и шока у взрослых и детей. В тот же день были рассмотрены вопросы постпункционной головной боли и блокад нервных сплетений под ультразвуковым контролем, особенности использования водителей ритма. Отдельное заседание было посвящено периоперационному периоду у больных с почечной и печеночной недостаточностью, а также вопросам создания «perioperative surgical home», так называемой периоперационной палаты. При этом были показаны положительные стороны данного этапа подготовки больного к проводимому оперативному вмешательству. В пятницу 13 декабря обсуждали проблемы индукции анестезии у гемодинамически нестабильных больных, лечения тяжелой черепно-мозговой травмы и проведения эпидуральной анальгезии, а во второй половине дня - анестезиологического пособия и высокотравматичных операций и лечения массивной кровопо- тери. В субботу 14 декабря были проведены сессии по анестезиологическому обеспечению у больных с ожирением, лечению хронической боли и регионарным методам лечения. Отдельное заседание Европейского общества анестезиологии (EuropeanSocietyofAnesthesiology) состоялось 15 декабря. Обсуждались вопросы безопасного использования кислорода в периоперационном периоде, протективной искусственной вентиляции легких во время анестезиологического пособия и современная профилактика тромбоэмболии легочной артерии.

В завершающий день ассамблеи профессором GeorgeSilvayбыло организовано посещение крупной онкологической клиники Нью-Йорка Memorial SloanKettering Cancer Center. Участники ассамблеи посетили операционные и отделение анестезиологии-реаниматологии, ознакомились с оборудованием и особенностями работы анестезиологов-реаниматологов данной клиники.

Заведующий лабораторией ФГБНУ «НИИОР», к. м. н. А. Н. Кузовлев, научный сотрудник ФГБНУ «НИИОР»,

к. м. н. Е. А. Мягкова

\title{
О работе Российского Национального совета по реанимации в 2014 г.
}

\section{Update on a Russian National Reanimatology Council in 2014}

Российский Национальный совет по реанимации (НСР) был создан в 2004 г. для объединения научнопрактического потенциала регионов России в области реаниматологии, анализа накопленного опыта, создания единых программ обучения методам проведения реанимационных мероприятий, унифицированных методик, соответствующих международным требованиям (рис. 1).

С 2004 г. Российский НСР является полноправным членом Европейского совета по реанимации (ЕСР) и эксклюзивным представителем интересов России в нем. Сотрудничество с ЕСР осуществляется на основе договора. Учредителем Российского НСР является НИИ общей реаниматологии им. В. А. Неговского. Цель создания Российского НСР - разработка и внедрение унифицированных программ обучения навыкам реанимационных мероприятий в соответствии с международными рекомендациями. Президент Российского НСР - член-корреспондент РАН, заслуженный деятель науки РФ, лауреат Премии Правительства РФ, директор НИИ общей реани-

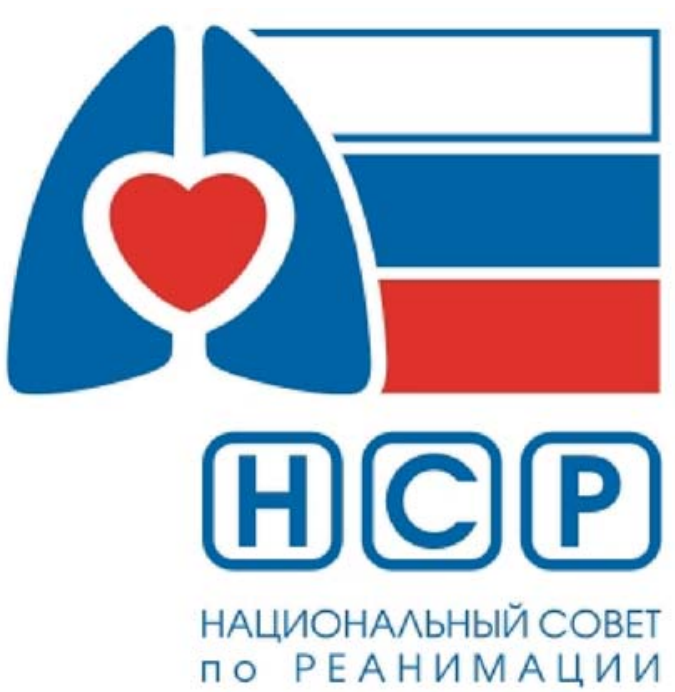

Рис. 1. Логотип Российского Национального совета по реанимации. 
матологии им. В. А. Неговского, профессор Мороз Виктор Васильевич.

Российский НСР организует на территории РФ проведение следующих курсов ЕСР: сердечно-легочная реанимация и автоматическая наружная дефибрилляция для провайдеров (с 2008 г.); сердечно-легочная реанимация и автоматическая наружная дефибрилляция для инструкторов (с 2010 г.); курсы по расширенным реанимационным мероприятиям (с 2014 г.); курсы по неотложным реанимационным мероприятиям (с 2014 г.); общий инструкторский курс (проводится с 2014 г. совместно с преподавателями ЕСР).

Данные курсы проводятся строго в соответствии с методиками и рекомендациями ECP, по единому образцу на всей территории РФ, с контролем качества со стороны Российского НСР. Все учебные материалы, используемые на курсах Российского НСР, являются официальными переводами образовательных материалов Европейского совета по реанимации. На курсах ЕСР обязательным является использование стандартных наборов учебных материалов и учебных программ ЕСР. Успешно завершившие курс участники получают сертификат ЕСР (на русском языке). Всего к настоящему моменту на курсах Российского НСР подготовлено более 2000 провайдеров и более 500 инструкторов.

Преподавательский состав Российского НСР в настоящее время включает в себя одного директора курсов и 40 инструкторов. Все инструкторы Российского НСР являются специалистами с высшим медицинским образованием, 90\% из них - врачи анестезиологи-реаниматологи, среди них 5 докторов медицинских наук (2 профессора) и 16 кандидатов медицинских наук. Информация об инструкторах Российского НСР доступна по ссылке http://niiorramn.ru/council/teachers.php и в группа Российского HCP www.vk.com/rusnrc.

В 2008 г. значительно увеличилось количество проводимых Российским НСР курсов и расширился их спектр (рис. 2), увеличилось количество курсов в регионах страны (с $67 \%$ в 2013 г. до 86\% в 2014 г.; рис. 3) и нагрузка на инструкторов (рис. 4).

В 2014 г. в рамках договора между Российским НСР и Европейским советом по реанимации (ЕСР) было проведено: 1 курс по расширенным реанимационным мероприятиям (Advanced life support), 1 общий инструкторский курс (Generic instructor course), 52 курса по базовой реанимации и автоматической наружной дефибрилляции для провайдеров (CPR/AED Provider) и 4 курса по базовой реанимации и автоматической наружной де-

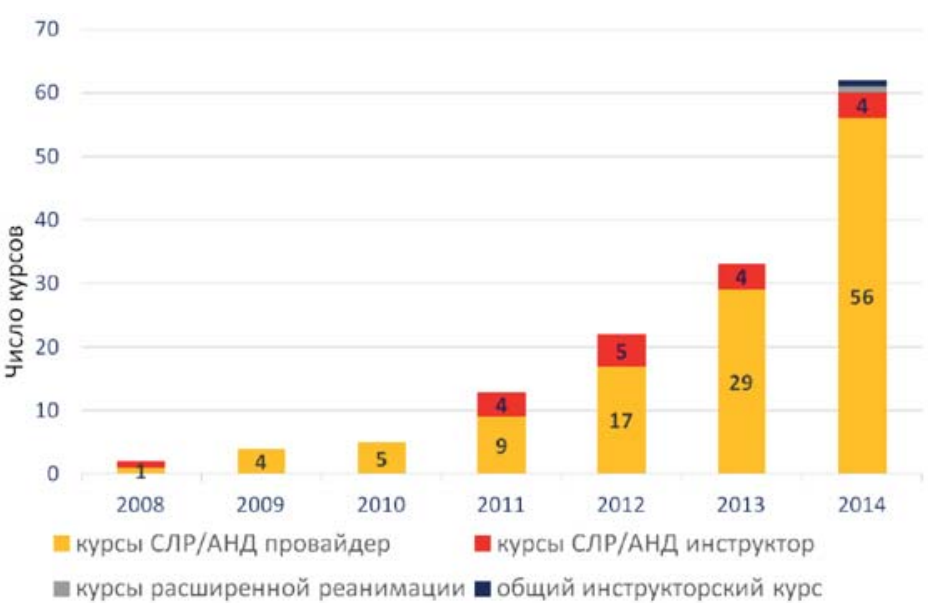

Рис. 2. Общее число курсов проведенных Российским НСР в 2008-2014 гг.

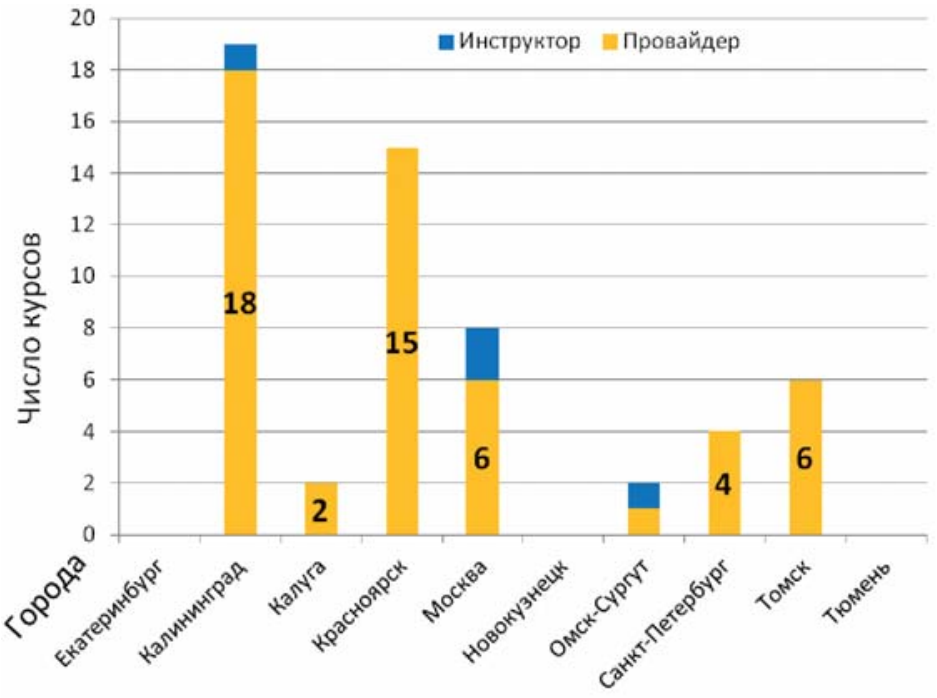

Рис. 3. Число курсов проведенных Российским НСР в регионах страны в 2014 г.

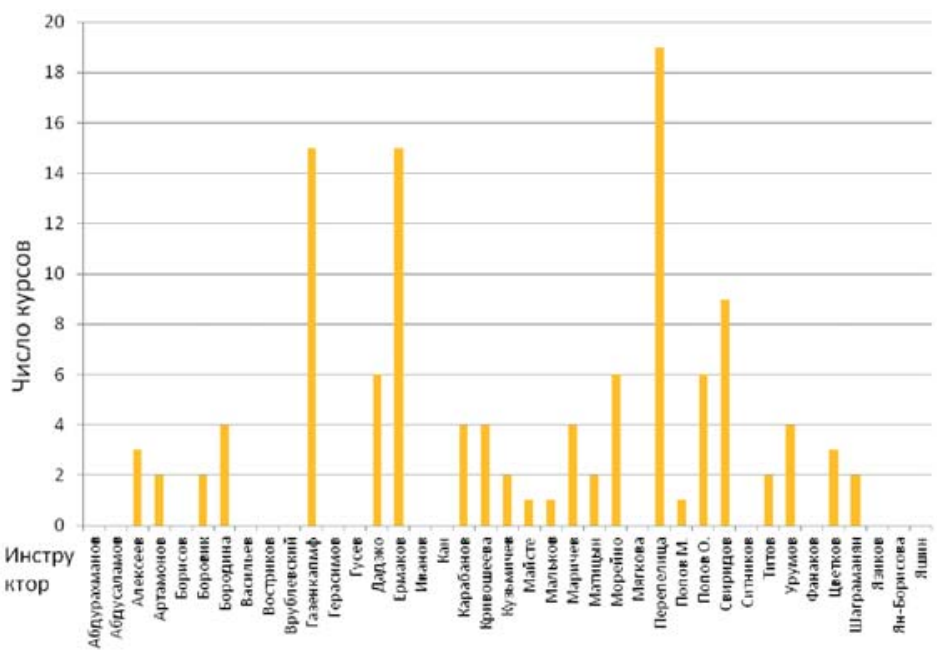

Рис. 4. Нагрузка на полноправных инструкторов Российского HCP в 2014 r. 
фибрилляции для инструкторов (CPR/AED Instructor), на которых подготовлено 557 провайдеров. 8-9 апреля 2014 г. были проведены первые курсы базовой реанимации для провайдеров и инструкторов в Омске на базе Омской государственной медицинской академии. Подписан договор о сотрудничестве. В настоящее время сотрудник Омской государственной медицинской академии является полноправным инструктором по базовой реанимации - д.м.н., профессор Мальков Олег Алексеевич.

23-24 апреля 2014 г. были проведены первые курсы базовой реанимации для провайдеров в Томске на базе Сибирского государственного медицинского университета и учебно-тренингового центра «Защита». Подписан договор о сотрудничестве. В настоящее время сотрудник Сибирского государственного медицинского университета является полноправным инструктором по базовой реанимации - к.м.н., доцент Дадэко Сергей Михайлович.

В 2014 г. Российским НСР продолжено сотрудничество с Федеральным медико-биологическим агентством России (г. Москва), Федеральным центром сердца, крови и эндокринологии им. В. А. Алмазова (г. СанктПетербург), Балтийским Федеральным Университетом им. И. Канта (г. Калиниград), Тюменским кардиологическим центром (г. Тюмень), Красноярской ассоциацией анестезиологов-реаниматологов (г. Красноярск), Российским Союзом спасателей. Подписаны договоры о сотрудничестве и проведении курсов провайдеров с ООО «Арибрис» и ООО «Медис».

Благодаря работе инструкторов Российского НСР в 2014 г. было выполнено оснащение международного аэропорта г. Калининград автоматическим наружным дефибриллятором.
В феврале 2014 г. были проведены первые в России курсы расширенной реанимации (Advanced Life Support, 16-17.02.2014) и курсы инструкторов (Generic Instructor Course, 18-19.02.2014). В данных курсах приняли участие 6 полноправных инструкторов Российского НСР, которые успешно их завершили. Курсы были проведены преподавателями ECP: Dr. Carsten Lott (Майнц, Германия), Dr. Andrew Lockey (Галифакс, Великобритания), Dr. Alan Hargreaves (Лидс, Великобритания), Dr. Dusan Vlahovic (Любляна, Словения). Проведение следующих куров расширенной реанимации запланировано на январь 2015 г.

В апреле 2015 г. планируется проведение следующей серии курсов расширенной реанимации (Advanced Life Support, 8-9.04.2015 и 10-11.05.2015). Данные курсы будут проведены с участием преподавателей ЕСР. По результатам данных курсов будет сформирована команда из 7 инструкторов по курсу расширенной реанимации.

Информация о предстоящих курсах доступна в календаре курсов ECP (www.erc.edu), на сайте НИИ общей реаниматологии им. В. А. Неговского (www.niiorramn.ru/council), в группе Российского НСР www.vk.com/rusnrc и журнале «Общая реаниматология».

Президент Российского национального
совета по реанимации
Заслуженный деятель науки России
член-корр. РАН, профессор
В. В. Мороз,
директор курсов по сердечно-легочной
реанимации Российского национального
совета по реанимации,
к.м.н. А. Н. Кузовлев

